\title{
Nutrient Density to Climate Impact index is an inappropriate system for ranking beverages in order of climate impact per nutritional value
}

\section{Dear Editors,}

A recent paper published in Food \& Nutrition Research contributes to the important research area of how to achieve nutritional goals while reducing the amount of greenhouse gas (GHG) emissions from the food system (1). The paper introduced a novel method of measuring the nutrient density of a food or drink in comparison to GHG emissions associated with the production, manufacturing, packaging, and transportation of that food or drink, using a life-cycle perspective - an index called Nutrient Density to Climate Impact (NDCI). The authors of the paper used the NDCI index to compare eight beverages: milk, soft drink, orange juice, beer, wine, bottled carbonated water, soy drink, and oat drink. The NDCI index for milk was higher than for the other beverages, and the authors concluded that 'milk both has the highest nutrient density per se, and has the highest nutrient density in relation to GHG emissions of the compared beverages. We also conclude that the NDCI index is a tool that facilitates inclusion of a nutritional aspect of the climate debate.'

We are concerned that the NDCI index is flawed, as the ranking of the beverages produced by the index is dependent on an arbitrary choice of threshold for contributing to the Nordic Nutrition Recommendations (NNR). The NDCI index is calculated as follows: density per global warming potential by the proportion of nutrients within the food that provide greater than $5 \%$ of the recommended intake, according to the NNR. Table 1 shows the results of changing this arbitrary term in the following ways - replacing the arbitrary term with 1 (so that the $\mathrm{NDCI}=A / B$ ); replacing the $5 \%$ of the recommended intake term with $1,2,10$, and $20 \%$ of the recommended intake. It is clear that the ranking of the beverages is dependent on the arbitrary term $C$. Milk only achieves the highest NDCI score when $C$ is set at 5 or $10 \%$ of the NNR, and ceases to have the highest score if $C$ is set at $20 \%$ of the NNR (when orange juice achieves a higher score). When $C$ is set with a value lower than $5 \%$, soy drink achieves a higher NDCI score.

One of the authors of the paper (Professor Drewnowski) has vast experience in developing nutrient density scores for foods, which have been used for developing nutrient profile models and for assessing the cost per nutrient density of a variety of foods and food groups (2-5). To our knowledge, none of the previous applications of nutrient density scores developed by Professor Drewnowski have incorporated a term that scales nutrient density by the proportion of nutrients over an arbitrary selected level (such as the arbitrary term $C$ used in the NDCI index). Table 1 also shows the results if this term is removed entirely from the NDCI index - here

$\mathrm{NDCI}=\frac{A}{B} \times C$

$$
\begin{aligned}
& A=\sum_{21 \text { nutrients }}\left(100 \times \frac{\text { Amount of nutrient in } 100 \mathrm{~g} \text { of food }}{\text { Recommended intake of nutrient }}\right) ; \\
& B=\mathrm{CO}_{2} e \text { associated with } 100 \mathrm{~g} \text { of food; } \\
& C=\frac{\text { Number of nutrients in food } \geq 5 \% \text { of recommended intake }}{21} .
\end{aligned}
$$

Here, $A$ is a measure of nutrient density, $B$ is a measure of the 'global warming potential' of the food, and $C$ is an arbitrary term, which scales the measure of nutrient soy drink achieves the highest score (indicating greater nutrient density per GHG emissions) followed by oat drink, then orange juice, and then milk. 
Table 1. Results from modified versions of the NDCI index, with the following modifications (1) arbitrary term $C$ removed from the index; (2) arbitrary term $C$ set at $1 \%$ of NNR; (3) arbitrary term $C$ set at $2 \%$ of NNR; (4) arbitrary term $C$ set at $5 \%$ of NNR; (5) arbitrary term $C$ set at $10 \%$ of NNR; (6) arbitrary term $C$ set at $20 \%$ of NNR

\begin{tabular}{lcccccc}
\hline Food & NDCl (I) & NDCl (2) & NDCl (3) & NDCl (4) ${ }^{\mathrm{a}}$ & NDCl (5) & NDCl (6) \\
\hline$C=$ & 1 & I\% of NNR & 2\% of NNR & $5 \%$ of NNR & $10 \%$ of NNR & $20 \%$ of NNR \\
Milk & 1.27 & 1.09 & 0.97 & $\mathbf{0 . 5 5}$ & $\mathbf{0 . 2 4}$ & 0.06 \\
Soft drink & 0.06 & 0.01 & 0.01 & 0.00 & 0.00 & 0.00 \\
Orange juice & 1.48 & 1.05 & 0.77 & 0.28 & 0.07 & 0.07 \\
Beer & 0.18 & 0.05 & 0.03 & 0.00 & 0.00 & 0.00 \\
Red wine & 0.12 & 0.04 & 0.02 & 0.01 & 0.00 & 0.00 \\
Mineral water & 0.20 & 0.00 & 0.00 & 0.00 & 0.00 & 0.00 \\
Soy drink & 1.77 & 1.26 & 1.01 & 0.25 & 0.00 & 0.00 \\
Oat drink & 1.52 & 0.87 & 0.58 & 0.07 & 0.00 & 0.00 \\
\hline
\end{tabular}

${ }^{a}$ Results reported in the original paper.

Note. For each set of results, the beverage with the highest NDCI is presented in bold.

We note that three of the authors of the paper (Smedman, Lindmark-Månsson, and Modin Edman) were funded by the Swedish Dairy Council. While these funding sources were appropriately declared in the 'conflicts of interest' section of the paper, given the results displayed in Table 1, we must question whether the funding source influenced the development of the NDCI index in order to produce favourable results for milk.

Sincerely,

Peter Scarborough and Mike Rayner British Heart Foundation Health Promotion

Research Group

Department of Public Health University of Oxford, UK

\section{References}

1. Smedman A, Lindmark-Månsson H, Drewnowski A, Modin Edman A-K. Nutrient density of beverages in relation to climate impact. Food Nutr Res 2010; 54: 5170. DOI: 10.3402/fnr.v54i0. 5170.

2. Drewnowski A. Concept of a nutritious food: toward a nutrient density score. Am J Clin Nutr 2005; 82: 721-32.

3. Drewnowski A, Fulgoni III V. Nutrient profiling of foods: creating a nutrient-rich food index. Nutr Rev 2008; 66: 23-39.

4. Drewnowski A. Defining nutrient density: development and validation of the nutrient rich foods index. J Am Coll Nutr 2009; 28: 421S-26S.

5. Darmon N, Darmon M, Maillot M, Drewnowski A. A nutrient density standard for vegetables and fruits: nutrients per calorie and nutrients per unit cost. J Am Diet Assoc 2005; 105: 1881-7. 